\title{
Hepatic interferon $\gamma$ and tumor necrosis factor $\alpha$ expression in infants with neonatal cholestasis and cytomegalovirus infection
}

\author{
Himali Meshram', Shilpa Velhal², Varsha Padwal², Jyoti Sutar², Ravi Kadam², Jacinta Pereira², Gauri Bhonde³, \\ Kalyani Karandikar ${ }^{3}$, Vikrant Bhor ${ }^{3}$, Vainav Patel ${ }^{3}$, Naman S. Shetty', Ira Shah ${ }^{1}$ \\ 'Bai Jerbai Wadia Hospital for Children, Mumbai, India \\ Indian Council of Medical Research (ICMR), New Delhi, India \\ ${ }^{3}$ National Institute for Research in Reproductive Health (NIRRH), Mumbai, India
}

\begin{abstract}
Aim of the study: To determine the hepatic interferon $\gamma$ (IFN- $\gamma$ ) and tumor necrosis factor $\alpha$ (TNF- $\alpha)$ levels in infants with neonatal cholestasis (NC) and associated cytomegalovirus (CMV) infection.

Material and methods: This study was conducted in 21 infants with NC over a period of 6 months from June 2017 to December 2017 to determine the hepatic IFN- $\gamma$ and TNF- $\alpha$ levels in infants with NC and associated CMV infection.

Results: IFN- $\gamma$ levels were positive in $16(80 \%)$, low positive in $3(16 \%)$ and negative in $1(5 \%)$ patients. High positive and positive TNF- $\alpha$ levels were seen in 9 (56.3\%) patients with positive liver CMV PCR and low positive levels were seen in $7(43.7 \%$ ) patients with positive liver CMV PCR (odds ratio [OR] = 2.6). Positive IFN- $\gamma$ was present in $13(81.3 \%)$ patients with positive liver CMV PCR and low positive or negative IFN- $\gamma$ was seen in $3(18.7 \%)$ patients with positive liver CMV PCR $(O R=2.2)$. Six $(60 \%)$ patients with positive or high positive TNF- $\alpha$ levels in liver tissue had biliary atresia (BA) whereas $7(77.7 \%)$ with low positive TNF- $\alpha$ levels had non-BA neonatal hepatitis $(O R=5.25)$. Six $(37.5 \%)$ patients with positive IFN- $\gamma$ had BA whereas $2(50 \%)$ patients with low positive or negative IFN- $\gamma$ had $B A(O R=0.6)$.

Conclusions: There is high prevalence of CMV in liver tissues in patients with NC and elevated TNF- $\alpha$ and IFN- $\gamma$ levels are seen in these patients. Elevated TNF- $\alpha$ is also seen in patients with BA. The association of elevated TNF- $\alpha, B A$ and CMV infection needs to be evaluated further.
\end{abstract}

Key words: immunochemistry, CMV, neonatal cholestasis.

Address for correspondence:

Dr. Ira Shah, Bai Jerbai Wadia Hospital for Children, Acharya Donde Marg, Mumbai-400012, India, e-mail: irashah@pediatriconcall.com

\section{Introduction}

Cytomegalovirus (CMV) is the largest of the herpes viruses and commonest cause of congenital infections $[1,2]$. CMV affects both adults and children and has a worldwide distribution. Incidence of congenital $\mathrm{CMV}$ infection ranges from $0.2 \%$ to $2.4 \%$ of all live births [3]. Immune responses in the fetus, the mother, and the placenta play a complex role in conferring immunity against congenital CMV infection [4]. An important consideration in the analysis of the cytokine profile of the congenitally CMV-infected infant is the fact that infant immunocytes produce smaller amounts of cytokines than do comparable adult cells. Cytokines such as interleukin (IL)-1 $\beta$, IL-12, IL-17, IL-18, IL-23, and tumor necrosis factor $\alpha$ (TNF- $\alpha$ ) are proposed to be important in the context of perinatal viral transmission [4]. Secretion of interferon $\gamma($ IFN- $\gamma)$ through the activation and differentiation of naive CD8 T cells to effector/memory cells in immunocompetent hosts is 
observed in primary CMV infection. A higher rate of CMV diseases in congenital infection is noted in children with alteration of these responses during the perinatal period [5]. An assessment of CMV-specific CD4 and CD8 T cell responses by Özdemir et al. including 87 allogeneic stem cell transplant recipients found that lower TNF- $\alpha$-producing fractions of tetramer-staining CMV specific CD8 T cells were seen in individuals who experienced CMV antigenemia compared to subjects who did not [6].

Neonatal cholestasis (NC) affects 1 in 2500 infants in the West. In India it constitutes 19\% to 33\% of all chronic liver diseases in children reporting to tertiary care [7]. The herpes group virus, especially CMV, was implicated in the development of intrahepatic NC by previous studies based on serological testing [8]. Previously we have detected a significant prevalence of CMV by PCR in hepatic biopsies in NC [9]. The present study seeks to evaluate whether this prevalence is linked to increased expression of well-known immunological markers of inflammation such as IFN $-\gamma$ and TNF- $\alpha$.

\section{Material and methods}

\section{Study design}

This study was conducted in the pediatric hepatology and infectious diseases unit of our hospital from May 2017 to November 2017. Twenty-one consecutive infants with NC (onset of jaundice before 3 months of age) were included in the study after approval from the ethics committee. Children who had onset of jaundice after 3 months of age, or those who already had undergone Kasai surgery or were already on anti-herpes agents, were excluded from the study. All patients underwent baseline investigations such as hemogram, liver function tests, ultrasound abdomen and $\mathrm{TORCH}$ ELISA immunoglobulin (Ig)M and IgG as part of NC workup. Infants with $\mathrm{NC}$ underwent liver biopsy as per the guideline to approach NC as per the Indian Academy of Pediatrics (IAP) [10]. Patients who did not require a liver biopsy were excluded from the study. On the liver tissue apart from histology on light microscopy, CMV PCR and immunochemistry for IFN- $\gamma$ and TNF- $a$ were done. In all patients blood CMV PCR was also done. Other investigations such as HIDA scan and echocardiography were done as per the IAP guideline whenever required [10]. Patients were divided into a CMV infected group (liver CMV PCR positive and/or blood CMV PCR positive) and CMV uninfected group (CMV PCR negative in both samples) and immune correlates were compared between the 2 groups.
Immune correlates were also compared in patients with biliary atresia (BA) who were CMV infected and non-infected. Patients were classified as per diagnosis to have $\mathrm{BA}$ or non-BA neonatal hepatitis. The diagnosis of BA was made on the basis of histopathology reports with liver architecture showing an increase in portal connective tissue with ductular proliferation, hepatocytes showing mild ballooning, feathery change and/or pseudoacinar formation with intrahepatic, intracanalicular and/or intrasinusoidal bile stasis. The portal plate showed liver tissue, bile ductular proliferation with periductular fibrosis, inflammation and bile lakes with bile ductular diameter from $<50 \mu \mathrm{m}$ to $>150 \mu \mathrm{m}$. All other samples were diagnosed as nonBA neonatal hepatitis.

\section{Normal parameters}

Patients were classified to have low birth weight if weight was less than $2.5 \mathrm{~kg}$ at birth. They were classified to be malnourished if their weight fell below the third percentile on the World Health Organization (WHO) growth chart. Normal levels of serum glutamic oxaloacetic transaminase (SGOT), serum glutamate pyruvate transaminase (SGPT), alkaline phosphatase, and $\gamma$-glutamyl transpeptidase (GGTP) were up to $38 \mathrm{IU} / \mathrm{l}$, up to $27 \mathrm{IU} / \mathrm{l}, 57-180 \mathrm{IU} / \mathrm{l}, 9-38 \mathrm{IU} / 1 \mathrm{respec}-$ tively according to our laboratory. Normal serum total bilirubin, direct bilirubin, and albumin levels were $0.3-1.2 \mathrm{mg} / \mathrm{dl}, 0-0.2 \mathrm{mg} / \mathrm{dl}$ and $1.2-2.8 \mathrm{gm} / \mathrm{dl}$ respectively. Patients were classified to have cirrhosis on the basis of ultrasonography or histopathology report.

\section{Transport of samples}

$2 \mathrm{ml}$ blood for CMV PCR was collected in EDTA and transported to the National Institute for Research in Reproductive Health (NIRRH) immediately. The liver tissue for CMV PCR and immunohistochemistry was collected in normal saline and transported immediately to the NIRRH. In case of delay, the tissue was kept in the freezer at $-20^{\circ} \mathrm{C}$ and then subsequently transported in an ice box.

\section{Methodology of CMV PCR}

Once the samples were received at the NIRRH, isolation of peripheral blood mononuclear cells (PBMCs) from whole blood was done and extraction of DNA from PBMCs and the liver tissue samples was done using a Qiagen DNA extraction kit. Actin PCR and an agarose gel (2\%) were used to ensure that the DNA extraction worked correctly. CMV PCR and agarose 
gel $(2 \%)$ were used to visualize the PCR results. Nested PCR was used for detection of CMV DNA. The region amplified was the morphological transforming region II (mtrII). Primers used for amplification of the DNA in round 1 wereCMTR1(CTGTCGGTGATGGTCTCTTC) and CMTR2 (CCCGACACGCGGAAAAGAAA), and in round 2 were CMTR3 (TCTCTGGTCCTGATCGTCTT) and CMTR4 (GTGACCTACCAACGTAGGTT).

Immunohistochemistry (IHC): IHC for both IFN- $\gamma$ and TNF- $\alpha$ were performed on 5 um sections of fixed liver biopsies using primary antibody $1: 50$ in $0.3 \%$ goat serum and secondary antibody, antirabbit HRP (horseradish peroxidase). A negative control was performed in every case. Images were captured using the cellSens software of the microscope. DAB and hematoxylin staining were done on the IHC images used. ImageJ compatible plugin software was used for analyzing cytoplasmic staining pattern by assigning a histogram profile for the deconvoluted DAB image. A staining score was calculated over 5 high-power fields. Scores were assigned as high positive $(3+)$, positive $(2+)$, low positive $(1+)$ and negative $(0)$. Liver samples were considered to express TNF- $\alpha$ and/or IFN- $\gamma$ when these glycoproteins were detected with any intensity in liver cells.

\section{Statistical analysis}

Association of CMV in patients with BA and nonBA NC was determined. Proportions were calculated by $\chi^{2}$ test or Fisher exact test and numerical data were assessed by $t$-test. $P$ value of $<0.05$ was taken as statistically significant.

\section{Results}

The total numbers of patients included in the study was 21 . The mean age at the time of presentation was $2.5 \pm 1.6$ months. Male : female ratio was 12 : 9 . The mean birth weight was $2.74 \pm 0.58 \mathrm{~kg}$. 17 (81\%) patients were born at full term and 4 (19\%) were born prematurely. Jaundice and hepatomegaly were present in all patients, 16 (76.2\%) had clay stools, 2 (9.5\%) had low birth weight and $2(9.5 \%)$ patients had malnutrition. Liver function tests revealed a mean bilirubin level of $12.1 \pm 7.0 \mathrm{mg} / \mathrm{dl}$ with direct bilirubin of $9.4 \pm 5.0 \mathrm{mg} / \mathrm{dl}$, SGOT of $244.7 \pm 143.8 \mathrm{IU} / \mathrm{l}$, SGPT of $162.8 \pm 162.0 \mathrm{IU} / \mathrm{l}$, total proteins of $5.8 \pm 0.7 \mathrm{gm} / \mathrm{dl}$, albumin of $3.1 \pm 0.5 \mathrm{gm} / \mathrm{dl}$, prothrombin time (PT) of 23.9 $\pm 22.7 \mathrm{~s}$, international normalized ratio (INR) of $1.8 \pm 1.3$,

Table 1. Details of each patient

\begin{tabular}{|c|c|c|c|c|c|c|}
\hline & CMV IgM positive & CMV IgG positive & Blood CMV PCR positive & Liver CMV PCR positive & IFN- $\gamma$ levels & TNF- $\alpha$ levels \\
\hline Patient 1 & Yes & No & Yes & Yes & 2 & 2 \\
\hline Patient 2 & No & Yes & Yes & Yes & - & - \\
\hline Patient 3 & Yes & Yes & Yes & Yes & 2 & 0.2 \\
\hline Patient 4 & No & Yes & Yes & Yes & 0.8 & 2.6 \\
\hline Patient 5 & No & Yes & Yes & No & 2 & 1 \\
\hline Patient 6 & No & Yes & Yes & Yes & 2 & 1.2 \\
\hline Patient 7 & No & Yes & Yes & Yes & 1.8 & 2 \\
\hline Patient 8 & No & No & Yes & Yes & 2 & - \\
\hline Patient 9 & Yes & Yes & Yes & Yes & 1.8 & 2 \\
\hline Patient 10 & Yes & No & Yes & Yes & 2 & 1.6 \\
\hline Patient 11 & No & No & Yes & Yes & 1.6 & 2 \\
\hline Patient 12 & No & No & Yes & Yes & 2 & 1 \\
\hline Patient 13 & No & Yes & No & Yes & 1.8 & 1 \\
\hline Patient 14 & No & No & Yes & Yes & 1.4 & 1.4 \\
\hline Patient 15 & No & Yes & Yes & Yes & 1.8 & 1.2 \\
\hline Patient 16 & No & Yes & Yes & Yes & 2 & 2 \\
\hline Patient 17 & No & Yes & Yes & Yes & 2 & 1.8 \\
\hline Patient 18 & No & Yes & Yes & Yes & 0.4 & 1 \\
\hline Patient 19 & Yes & Yes & Yes & No & 1 & 1.4 \\
\hline Patient 20 & Yes & No & No & No & 1.8 & 2 \\
\hline Patient 21 & No & Yes & Yes & Yes & 2 & 2 \\
\hline
\end{tabular}

CMV - cytomegalovirus, IgG - immunoglobulin G, IgM - immunoglobulin M, IFN- - interferon $\gamma$, TNF- $\alpha$ - tumor necrosis factor $\alpha$ 
alkaline phosphatase of $766.7 \pm 465.3 \mathrm{IU} / \mathrm{l}$ and GGTP of $252.2 \pm 334.6 \mathrm{IU} / \mathrm{l}$. Eight (38\%) patients were detected to have BA, $12(57.1 \%)$ patients had neonatal hepatitis, $1(4.76 \%)$ had paucity of bile ducts. Fourteen (66.6\%) patients were treated with valganciclovir. Nine (42.8\%) patients recovered, 4 (19\%) patients developed chronic liver disease, $2(9.5 \%)$ are newly diagnosed and need to be followed up and $6(28.5 \%)$ were lost to follow-up.

Blood CMV PCR was positive in 19 (90.47\%) patients, liver CMV PCR was positive in 18 (85.71\%) patients, CMV IgM was positive in $6(28.5 \%)$ patients and CMV IgG was positive in 14 (66.6\%). The details of each patient are depicted in Table 1. TNF- $\alpha$ levels in liver tissue sample were available for 19/21 patients by IHC (in remaining 2 , the tissue got spoiled). IFN- $\gamma$ levels in liver tissue sample by IHC were available for $20 / 21$ patients. TNF- $\alpha$ levels were high positive in $1(5.3 \%)$, positive in $9(47.4 \%)$ and low positive in $9(47.4 \%)$. IFN- $\gamma$ levels were positive in $16(80 \%)$, low positive in $3(16 \%)$ and negative in $1(5 \%)$ of patients. Factors associated with positive and low positive levels of TNF- $\alpha$ and IFN- $\gamma$ are depicted in Tables 2, 3 and 4. High positive and positive TNF- $\alpha$ levels were seen in 9 (56.3\%) patients with positive liver CMV PCR and low positive levels were seen in 7 (43.7\%) patients with positive liver CMV PCR (odds ratio $[\mathrm{OR}]=2.6$, 95\% CI: -0.2-34.5). Positive IFN- $\gamma$ was present in 13 (81.3\%) patients with positive liver CMV PCR and low positive or negative IFN $-\gamma$ was seen in $3(18.7 \%)$ patients with positive liver CMV PCR ( OR $=2.2$, 95\% CI: $-0.14-32.5)$. Six (60\%) patients with positive or high positive TNF- $\alpha$ levels in liver tissue had BA whereas 7 (77.7\%) with low positive TNF- $\alpha$ levels had non-BA neonatal hepatitis ( $\mathrm{OR}=5.25,95 \% \mathrm{CI}$ : -0.7-39.5). Six (37.5\%) patients with positive IFN- $\gamma$ had BA whereas 2 (50\%) patients with low positive or negative IFN- $\gamma$ had BA (OR = 0.6, 95\% CI: $-0.1-5.4)$.

\section{Discussion}

CMV infections are present in about $1-2.4 \%$ of newborns in North America and India. A high prevalence of CMV is found in children with both intrahepatic and extrahepatic NC $[8,9]$ as was seen in our study where the CMV infection was present in 19 out of 21 patients studied. We also found that $80 \%$ had positive IFN- $\gamma$ of which $87.5 \%$ were CMV liver positive, 3 (15\%) had low positive results of which $2(66.6 \%)$ were CMV liver positive and $1(5 \%)$ had a negative test but was liver CMV positive. Tu et al. compared CMV-specific CD4 and CD8 T cell responses between asymptomatic young children and adults, and found deficiency of IFN- $\gamma$ in asymptomatic young children as compared to symptomatic children [11]. Studies of murine CMV indicated that CD4 $\mathrm{T}$ cells producing IFN- $\gamma$ are important for the control of CMV replication and shedding from epithelial sites [11]. Dorner et al. studied CMV infections in murine models and found that NK cells are a major source of the cytokines ATAC, IFN- $\gamma$, MIP-1, MIP1, and RANTES [12]. Compton et al. showed that CMV activates inflammatory cytokine responses. Inflammatory cytokines play a role in recruiting neutrophils and monocytes from the circulation to sites of infection. Interferon and interferon-stimulated gene are also induced by CMV particles during entry. Induction of inflammatory genes, such as those for interleukin (IL)-6, IL-7, IL-11, RANTES, and cyclooxygenase 2 (COX-2) and antiviral genes belonging to the interferon-stimulated gene family (ISGs) occurs in CMV-infected fibroblasts [13].

Ten infants in our study had positive or high positive TNF- $\alpha$, of whom $88.8 \%$ had positive liver CMV PCR, and 9 had low positive levels of TNF- $\alpha$, of whom 7 were liver CMV PCR positive. Increase in Th1-related genes TNF- $\alpha$, caspase-1, and STAT-1 in mice from the low dose CMV group compared to the control

Table 2. Factors associated with levels of tumor necrosis factor $\alpha$ (TNF- $\alpha$ ) and interferon $\gamma($ IFN- $\gamma$ )

\begin{tabular}{lccc}
\hline TNF- $\alpha$ & Positive + high positive $(\boldsymbol{n}=\mathbf{1 0})$ & Low positive $(\boldsymbol{n}=\mathbf{9})$ & $\boldsymbol{P}$-value \\
\hline Age (months) & $3.1 \pm 1.9$ & $2.3 \pm 1.2$ & 1 \\
\hline Bilirubin (mg/dl) & $11 \pm 7$ & $11.1 \pm 5.3$ & 1.1 \\
\hline SGOT (IU/l) & $237.8 \pm 158$ & $251.8 \pm 150$ & 0.557 \\
\hline SGPT (IU/l) & $147.9 \pm 126.2$ & $203.8 \pm 206$ & 0.0033 \\
\hline IFN- $\gamma$ & Positive $(\boldsymbol{n}=\mathbf{1 6})$ & Low positive + negative $(\boldsymbol{n}=4)$ & $\boldsymbol{P}$-value \\
\hline Age (months) & $3.1 \pm 1.9$ & $2.3 \pm 1.2$ & 1 \\
\hline Bilirubin (mg/dl) & $11.9 \pm 6.3$ & $8.6 \pm 3.9$ & 0.667 \\
\hline SGOT (IU/l) & $268.9 \pm 144.2$ & $131.8 \pm 111.2$ & 0 \\
\hline SGPT (IU/l) & $164.2 \pm 163.4$ & $188.8 \pm 188.6$ & 0.201 \\
\hline SGOT - serum
\end{tabular}

SGOT - serum glutamic oxaloacetic transaminase, SGPT - serum glutamate pyruvate transaminase 
Table 3. Factors associated with positive and low positive levels of tumor necrosis factor $\alpha$ (TNF- $\alpha$ )

\begin{tabular}{lccc}
\hline \multicolumn{1}{l}{ TNF- $\alpha$} & Positive + high positive $(\boldsymbol{n}=10)$ & Low positive $(\boldsymbol{n}=\mathbf{9})$ & P-value \\
\hline Gender & $5(50 \%)$ & $5(55.5 \%)$ & 1 \\
\hline Male & $5(50 \%)$ & $4(44.4 \%)$ & 0.582 \\
\hline Female & $9(90 \%)$ & $7(77.7 \%)$ & 1 \\
\hline Liver CMV PCR positive & $9(90 \%)$ & $8(88.8 \%)$ & 0.628 \\
\hline Blood CMV PCR positive & $4(40 \%)$ & $2(22.2 \%)$ & 0.628 \\
\hline CMV IgM positive & $6(60 \%)$ & $7(77.7 \%)$ & 0.1698 \\
\hline CMV IgG positive & & & \\
\hline Diagnosis & $6(60 \%)$ & $2(22.2 \%)$ & 0.8363 \\
\hline Biliary atresia & $4(40 \%)$ & $7(77.7 \%)$ & \\
\hline Neonatal hepatitis & & $4(44.4)$ & $1(11.1 \%)$ \\
\hline Outcome & $5(50 \%)$ & $1(11.1 \%)$ & \\
\hline Recovered & $2(20 \%)$ & $3(33.3 \%)$ & \\
\hline Chronic liver disease & $1(10 \%)$ & & \\
\hline On follow-up & $2(20 \%)$ & & \\
\hline Lost to follow-up & & \\
\hline CMV - cytomegalovirus, IgG - immunoglobulin G, IgM - immunoglobulin M &
\end{tabular}

Table 4. Factors associated with positive and low positive levels of interferon $\gamma($ IFN- $\gamma)$

\begin{tabular}{|c|c|c|c|}
\hline IFN- $\gamma$ & Positive $(n=16)$ & Low positive + negative $(n=4)$ & $P$-value \\
\hline \multicolumn{4}{|l|}{ Gender } \\
\hline Male & $9(56.25 \%)$ & $2(50 \%)$ & \multirow[t]{2}{*}{1} \\
\hline Female & $7(43.75 \%)$ & $2(50 \%)$ & \\
\hline Liver CMV PCR positive & $14(87.5 \%)$ & $3(75 \%)$ & 0.5088 \\
\hline Blood CMV PCR positive & $14(87.5 \%)$ & $4(100 \%)$ & 1 \\
\hline CMV IgM positive & $5(31.25 \%)$ & $1(25 \%)$ & 1 \\
\hline CMV IgG positive & $10(62.5 \%)$ & $3(75 \%)$ & 1 \\
\hline \multicolumn{4}{|l|}{ Diagnosis } \\
\hline Biliary atresia & $6(37.5 \%)$ & $2(50 \%)$ & \multirow[t]{2}{*}{1} \\
\hline Neonatal hepatitis & $10(62.5 \%)$ & $2(50 \%)$ & \\
\hline \multicolumn{4}{|l|}{ Outcome } \\
\hline Recovered & $7(43.75 \%)$ & $2(50 \%)$ & \multirow[t]{4}{*}{0.6508} \\
\hline Chronic liver disease & $3(18.75 \%)$ & $0(0 \%)$ & \\
\hline On follow-up & 1 & $1(25 \%)$ & \\
\hline Lost to follow-up & 5 & $1(25 \%)$ & \\
\hline
\end{tabular}

CMV - cytomegalovirus, IgG - immunoglobulin G, IgM - immunoglobulin $M$

groups were observed by Wen et al. [14]. Orange et al. in their study of murine CMV infection concluded that TNF- $\alpha$ is required in the induction of hepatic necrotic foci and liver enzymes in serum and that cytokines normally induced during an antiviral immune response can mediate pathology and have potentially direct consequences depending upon the immunocompetence of the host [15].
We also found that those with CMV PCR positive liver and blood samples had higher TNF- $\alpha$ and IFN- $\gamma$ levels. TNF- $\alpha$ levels were 2.5 times $(\mathrm{OR}=2.57)$ more positive and IFN- $\gamma$ levels were 2 times $(\mathrm{OR}=2.1)$ more positive in patients with liver CMV positive results. However, it is difficult to state whether the positive cytokine response of TNF- $\alpha$ and IFN- $\gamma$ in liver tissue samples in our study is due to CMV infection as hepat- 
ic cholestasis due to any cause would be accompanied by inflammatory responses $[16,17]$.

In primary infection of CMV, neonates have a delayed cell-mediated immune response as compared with that of adults with the same primary infection. In in vitro studies, neonatal $\mathrm{T}$ cells have shown reduced cytolytic activity against primary antigen, resulting in deficient IL-2 production. Though independent primary humoral and cellular immunity were detected in CMV congenitally infected newborns, the CMV-specific CD8+ T cell responses were seen with lower levels of IFN- $\gamma$ and higher IL-8 levels when compared with adults. The reduced immune responsiveness, Th2 response and the sustained IL-8 levels are responsible for low protective immunity, leading to uncontrolled viremia and severe clinical damage in congenitally infected newborns with CMV [18]. We have not compared our findings with CMV liver disease and immune correlates in adults to determine whether the immune storm is lesser as compared to adults.

We also found a stronger association of TNF- $\alpha$ with BA patients, suspecting CMV to be an important cause of BA. In one of our studies conducted at our institution it was found that $50 \%$ of patients with diagnosed BA had positive CMV liver PCR. Similarly, a study by Shen et al. had a CMV IgM positive rate of $48 \%$ in BA patients [19]. In patients with BA it was found that TNF- $\alpha$ levels were higher $(\mathrm{OR}=5.3)$ whereas IFN- $\gamma$ levels were lower $(\mathrm{OR}=0.6)$. Since it is the Th1 type immune response which leads to the production of cytokines such as TNF- $\alpha$, further studies are required to determine whether the Th1 immune response is responsible of causing BA and whether the TNF- $\alpha$ response in CMV is responsible for the BA.

The limitation of our study was that we had very few patients who were CMV uninfected by liver CMV PCR. Also, we did not have a control group of healthy infants who were tested for CMV infection and the immune correlates. In different parts of India, $80-90 \%$ of women of childbearing age are positive for CMV IgG antibodies [20,21]. Very little information is available about the incidence of active CMV infection in healthy infants in India though the incidence of congenital CMV has been reported to be 1-2.4\% [3]. A cross sectional study done in children from the age group 0 to 18 years screened for CMV IgG antibodies. The overall prevalence of CMV infection was $84 \%$. The prevalence of CMV infection in age groups 1-28 days and 28 days to 1 year were $92.8 \%$ and $87.5 \%$ respectively, suggesting that $\mathrm{CMV}$ infection is highly prevalent in Indian children. However, passive transfer of CMV IgG antibodies from the mother could be a confounding factor [22]. Dollard et al. found presence of CMV IgG in 27\% of healthy children from 6 months to 5 years, of which 3 out of 13 positives were also CMV IgM positive, suggestive of recent primary infection. Of the 13 children, $69 \%$ were shedding CMV DNA in one or more bodily fluid [23]. In our study blood CMV PCR was positive in over $90 \%$ of the infants, suggesting that the presence of the virus in NC is greater than that in healthy children. Whether the CMV association can be proved will need further evaluation in case-control studies.

\section{Conclusions}

There is high prevalence of CMV in liver tissues in patients with NC. Elevated TNF- $\alpha$ and IFN- $\gamma$ levels are seen in these patients. Elevated TNF- $\alpha$ is also seen in patients with BA. The association of elevated TNF- $\alpha$, development of BA and CMV infection needs to be evaluated further in future studies.

\section{Disclosure}

The authors declare no conflict of interest.

\section{References}

1. Leung AK, Sauve RS, Davies HD. Congenital cytomegalovirus infection. J Natl Med Assoc 2003; 95: 213-218.

2. Chakravarti A, Kashyap B, Matlani M. Cytomegalovirus infection: An Indian perspective. Indian J Med Microbiol 2009; 27: 3-11.

3. Zucca C, Binda S, Borgatti R, et al. Retrospective diagnosis of congenital cytomegalovirus infection and cortical maldevelopment. Neurology 2003; 61: 710-712.

4. Schleiss MR. Cytomegalovirus in the neonate: immune correlates of infection and protection. Clin Dev Immunol 2013; 2013: 501801.

5. Arend SM, Kroes AC. Look and ye shall find... Cytomegalovirus infection in immunocompetent patients. Clin Infect Dis 2003; 37: 1607-1608.

6. Özdemir E, St John LS, Gillespie G, et al. Cytomegalovirus reactivation following allogeneic stem cell transplantation is associated with the presence of dysfunctional antigen-specific CD8 ${ }^{+}$ T cells. Blood 2002; 100: 3690-3697.

7. Pereira L, Stagno S, Hoffman M, Volanakis J. Cytomegalovirus infected cell polypeptides immune precipitated by sera from children with congenital and perinatal infections. Infect Immun 1983; 39: 100-108.

8. Oliveira NL, Kanawaty FR, Costa SC, Hessel G. Infection by cytomegalovirus in patients with neonatal cholestasis. Arq Gastroenterol 2002; 39: 132-136.

9. Goel A, Chaudhari S, Sutar J, et al. Detection of cytomegalovirus in liver tissue by PCR in infants with neonatal cholestasis. Pediatr Infect Dis J 2018; 37: 632-636.

10. Bhatia V, Bavdekar A, Matthai J, et al. Management of neonatal cholestasis: consensus statement of the pediatric gastroenterology chapter of Indian Academy of Pediatrics. Indian Pediatr 2014; 51: 203-210. 
11. Tu W, Chen S, Sharp M, et al. Persistent and selective deficiency of CD4+ T cell immunity to cytomegalovirus in immunocompetent young children. J Immunol 2004; 172: 3260-3267.

12. Dorner BG, Smith HR, French AR, et al. Coordinate expression of cytokines and chemokines by NK cells during murine cytomegalovirus infection. J Immunol 2004; 172: 3119-3131.

13. Compton T, Kurt-Jones EA, Boehme KW, et al. Human cytomegalovirus activates inflammatory cytokine responses via CD14 and Toll-like receptor 2. J Virol 2003; 77: 4588-4596.

14. Wen J, Xiao Y, Wang J, et al. Low doses of CMV induce autoimmune mediated and inflammatory responses in bile duct epithelia of regulatory $\mathrm{T}$ cell depleted neonatal mice. Lab Invest 2015; 95: 180-192.

15. Orange JS, Salazar-Mather TP, Opal SM, Biron CA. Mechanisms for virus-induced liver disease: tumor necrosis factor mediated pathology independent of natural killer and T cells during murine cytomegalovirus infection. J Virol 1997; 71: 9248-9258

16. Cai SY, Boyer JL. Studies on the mechanisms of bile acid initiated hepatic inflammation in cholestatic liver injury. Inflamm Cell Signal 2017; 4: e1561.

17. Kosters A, Karpen SJ. The role of inflammation in cholestasis: clinical and basic aspects. Semin Liver Dis 2010; 30: 186-194.

18. La Rosa C, Diamond DJ. The immune response to human CMV. Future Virol 2012; 7: 279-293.

19. Shen C, Zheng S, Wang W, Xiao XM. Relationship between prognosis of biliary atresia and infection of cytomegalovirus. World J Pediatr 2008; 4: 123-126.

20. Chakravarty A, Kashyap B, Rathi K. The seroepidemiological study on cytomegalovirus in women of childbearing age with special reference to pregnancy and maternal-fetal transmission. Indian J Pathol Microbiol 2005; 48: 518-521.

21. Gandhoke I, Aggarwal R, Lal S, Khare S. Congenital CMV infection in symptomatic infants in Delhi and surrounding areas. Indian J Pediatr 2006; 73: 1095-1097.

22. Kamalammal R, Balaji, Mohamed Sait Y. Age stratified seroprevalence of cytomegalovirus in children. Int J Pediatr Res 2016; 3: 351-355.

23. Dollard SC, Keyserling H, Radford K, et al. Cytomegalovirus viral and antibody correlates in young children. BMC Res Notes 2014; 7: 776. 